\title{
En torno a la identidad. La comunidad como trabajo *
}

\author{
JOSÉ BARATA-MOURA \\ Universidad de Lisboa
}

1

Para ahorrar tiempo, aún entre filósofos, cultores del logos que es también «palabra», no hay como entrar en materia.

Porque el ser —en la concreción de su realidad deveniente, y no sólo tras virtudes de plasticidad lingüística- es un $\pi \circ \lambda$ $\lambda \alpha \chi \hat{\omega} \varsigma$ $\lambda \varepsilon \gamma o ́ \mu \varepsilon v o v$, según la sentencia de Aristóteles ${ }^{1}$, puede la posición, la $\theta \varepsilon \dot{\sigma ı \varsigma}$, , de este enunciado temático («La península ibérica y Europa») retejer y reunir a un manojo de problemas ${ }^{2}$; pudo Saramago, sin enmatarse por innovaciones geológicas respecto de una teoría de la tectónica de las placas, fingir la citoriedad pirenaica, cortándose de su ensanche continental, como «barco que se afasta do porto e aponta ao mar outra vez desconhecido» ${ }^{3}$; podremos nosotros hechar de nuevo una mirada a esa categoría de «identidad», tan nuclear y estructurante de cualquier proyecto de construcción comunitaria.

La identidad, y sobremanera la identidad cultural, suele justificar, en tanto que evidencia inmediata, el hecho mismo de que haya comunidades.

Sin embargo, inmediatez y evidencia no cierran el paso al pensar; por el contrario, recubren y dibujan un horizonte que solicita su diligencia, su trabajado sondeo de mediación.

En tanto que ejercicio de vigilancia indagadora y de demanda de fundamento, la crítica - aunque sin despedir a la perplejidad, el «acicate insustituible de la reflexión filosófica», según Javier Muguerza ${ }^{4}$ - siempre despliega un transgredir, una incursión más allá de la mera datidad de las evidencias.

Quizás la transparencia ofuscante de lo idéntico custodie secretos hilos de que su luminosidad se entrama.

2

Toda identidad señala la persistencia de una determinación que sólo logra individuarse en un contorno de negaciones. La formulación lapidaria remonta a Spinoza: «determinatio negatio est» 5 .

El privilegio abstracto, «metafísico», del vector «demarcación» respalda conocidos planteamientos de polarizada dualización entre dominios de familiaridad y de extrañeza, de pertenencia y de exclusión, de camaradería y de hostilidad.

Carl Schmitt pudo, así, erigir la «amistad» y la «enemistad», una variación de la identidad delimitadora en clave «afectiva», en criterio fundamental de la repartición que define el ámbito de «lo político»: «Toda oposición [Gegensatz] religiosa, moral, económica, étnica u otra se convierte en una oposición política cuando es suficientemente fuerte para agrupar efectivamente [effektiv] a los hombres según amigo [Freund] y enemigo [Feind]» ${ }^{6}$.

* Este texto fue presentado en el Encuentro hispano-portugués de Filosofía sobre la «La Península Ibérica y Europa» celebrado en mayo de 2000, el cual fue auspiciado por el Instituto de Filosofía del Consejo Superior de Investigaciones Científicas y la Fundación «Afonso Henriques» de Zamora. 
Samuel Huntington, estribándose en las premisas de que la «identidad a cualquier nivel - personal, tribal, racial, civilizacional- sólo puede definirse en relación a un "otro" [other]», y de que «el "nosotros" civilizacional y el "ellos" extracivilizacional son una constante en la historia humana», propende a sacar la conclusión de que «es humano odiar. Para [su] autodefinición y motivación la gente necesita enemigos» 7 .

Por otra parte, un concentrarse exclusivo en la instancia «determinación» suele presentarnos (y representarnos) la «identidad» como uniforme monotonía, acervo estático de dispositivos fijados (o prefijados), idealizado promedio de rasgos decantados (y cantados también) que en permanencia se repiten.

Gilles Deleuze señala con acierto toda una vinculación del «primado de la identidad» a los «postulados de la representación» ${ }^{8}$.

Tiene sobre todo razón Hegel, cuando insiste en que «el mero representar [Vorstellen] saca, sin embargo, las cosas completamente de su conexión concreta [aus ihrem konkreten Zusammenhang], las singulariza» 9 .

En un cierto sentido — sólo desde lejos aludido por Nietzsche ${ }^{10}$ — la «representación» (Vorstellung, la «colocación delante») es también una Verstellung, en su doble acepción de «des-ubicación»y de «disimulación».

La representación disloca, en la medida en que —objectivación oblige - retira algo del flujo deveniente en el que se integra para considerarlo aparte, aisladamente; irrumpe, así, la dimensión «abstractiva» del entendimiento que representa.

En concomitancia, la «representación» involucra ocultación o disfraz de las distintas posibilidades que, en su dar a ver mismo, no retiene, y, desde luego, «disimula» la totalidad concreta en la que, en su contenido y en tanto que acto/resultado, se inscribe.
3

Es menester, por ende, pensar la identidad en su dinámica real, intentando sorprender el trabajo que desde su trasfondo elabora su determinación y el tenor efectivo de la negatividad que la traviesa, tejida y entretejida de relaciones multíplices.

Como Deleuze recuerda, bajo la identidad/simulacro representada, hormiguean alteridades y tensiones desatendidas: «Hay diferencias internas que dramatizan una Idea, antes de representar un objeto» ${ }^{11}$.

El planteamento seminal se encuentra todavía ya presente y activo en Hegel. «Identidad» (Identität) y «no-identidad» (Nichtidentität) ostentan, por igual, sus títulos y derechos, en el mundo de la positividad empírica; la «injusticia» o la «incorrección» (Unrecht) procede, empero, ontológicamente, de que se considerara a la una o a la otra como algo de «firme» (Festes) y de «realmente efectivo» (Wirkliches), cuando sólo «su movimiento» (ihre Bewegung), precisamente, «tiene verdad» (Warheit hat) ${ }^{12}$.

No hay identidad real fuera de ese proceso que enlaza — según modalidades muy distintas de relación- «identidad» $\mathrm{y}$ «noidentidad».

Una vez más, incumbe al pensar $-\mathrm{y}$, particularmente, al pensar filosófico- la quiebra de presuntas o precipitadas «evidencias» que, en el marco de la representación ordinaria, afloran y florecen.

Como ya Karel Košik señalaba, la Pseudokonkretheit es una «aparencia» (Schein) de autonomía y de «naturalidad» (ineluctabilidad) ${ }^{13}$, en el doble sentido de que «aparece» así, pero configura una «ilusión»; por eso tiene que ser sometida al escrutinio de la crítica.

De hecho, hay que transitar de un concepto abstracto, unilateral e inmediato de «identidad» a una concepción concreta, totalizada y dialéctica de su realidad. 
La identidad posibilita, sin duda, la identificación, de un ente, de un fenomeno, de una esencia $-\mathrm{y}$, en esa medida, indica $\mathrm{y}$ da a ver a unidades reconocibles. Pero ésta es la «identidad» inanalizada en el proceso que la sustenta o en el que consiste.

La identidad, considerada en sí misma y en su devenir, no es nunca mera tautología vacía de alteración, simple igualdad o repetición, sinónimo de mesmidad exclusiva.

La identidad identificativa es siempre movimiento y unidad de mismo y de otro; comporta y transporta en su seno, desde su interior mismo, la diversidad y la negación «resolviéndose» en la propia textura fluyente de aquello que se firma y afirma como siendo «un mismo», «ello propio».

La identidad verdadera, real, es siempre una identidad «viva» (aun cuando el ritmo del cambio que incorpora se explaya por períodos muy dilatados), entrelazada de diferencias en diálogo, en tensión, en conflicto: es la forma, unificada, de una multiplicidad estructurada y moviente.

No solamente la identidad apenas se pone como diferencia respecto de toda una esfera de alteridades, como en sí misma constantemente ella elabora y subsume un conjunto (más o menos extenso) de «diferentes». Sin este trabajo, retensivo y protensivo, de reconfiguración no hay identidad que perdure.

La momificación de lo idéntico - tan característica de enfoques tradicionalistas e integristas - no hace más que atestiguar, en registro de obsesiva denegación, su inexorable pasamiento.

Fuera de un proceso de refiguración, no queda más que reiteración inerte, a lo mejor, un material reciclable en otros itinerarios; una identidad sólo puede mantenerse, anclándose en los retos de la historia.
En términos de identidad, lo que sí hay que pensar $-\mathrm{y}$ reposa con frecuencia impensado- es, en el decir de Martin Heidegger (aunque en un marco doctrinario que no compartimos), la «co-pertenencia» (die Zusammengehörigkeit) de «identidad» y de «diferencia» ${ }^{14}$, en tanto que figuras o expresiones de la concreción deveniente del ser: múltiple y uno, uno y múltiple.

Heráclito se había dado cuenta ya de este pulsar: «Sinapses: enteros y no enteros, concorde-discorde, consonante-disonante, y de todas las cosas un, y de un todas las cosas» ${ }^{15}$.

Esta diferencia, que integra y compone la unidad de lo idéntico, no es un agregado suelto o calidoscópico de alteridades o de variaciones que se yuxtaponen y asocian; al contrario, ella es una dinámica de relación, una mediación entrañablemente constitutiva de la determinación misma de la identidad del supuesto, de la instancia, del proceso considerados.

Jacques Derrida, volviendo una mirada reflexionante hacia este tema, acuñó la categoría différance, «heterografiada» con una $a$, para significar esa tejedura de «remisiones» (renvois), ese «juego sistemático de diferencias» (jeu systématique de différences) ${ }^{16}$, ese esparcimiento y esa temporización que subtienden cualquier identidad.

Emmanuel Lévinas, en registro antropológico ahora, no deja de subrayar una constitutiva «endogeneización» de la identidad como proceso, buscando de explotar «un viraje de la convexidad en concavidad» (un retournement de la convexité en concavité): «La identidad del individuo no consiste en ser semejante [pareil] a si mismo $\mathrm{y}$ en dejarse identificar desde afuera por el índice que lo designa, sino que en ser lo mismo -en ser si mismo, en identificarse desde el interior» ${ }^{17}$.

Hegel sigue siendo, sin embargo, y a pesar de la clave idealista de su doctrina, 
la referencia basilar respecto de todos estos desarrollos, con su honda comprensión del nudo fundamental de contraditoriedad «resuelta» que sostiene y anima, en concreto y como concreción, toda identidad.

«La identidad abstracta consigo [mismo]», se puede leer en la Ciencia de la Lógica, «no es aún vitalidad [Lebendigkeit] ninguna [...]. Algo, por lo tanto, sólo está vivo, en la medida en la que contiene en sí la contradicción [Widerspruch]» ${ }^{18}$.

6

En su propio tenor identificativo y definitorio, la identidad es siempre un complejo dinámicamente estructurado (y no solamente yuxtapuesto) de elementos y de relaciones.

La sucesividad de los reconocimientos no deja intocado a lo reconocido; éste adquiere una calidad cultural enriquecida en los nuevos circuitos de comunicación extendida de que pasa a formar parte.

Por otro lado, lo que en un curso de identidad se da a reconocer es ello mismo vitalidad en desarrollo, reconfiguración plástica de un ser que como historicidad persiste, quiere decir, que en tanto que vector sigue escribiéndose.

La permanencia, que hace conocer algo como idéntico y que permite reconocerlo como tal, no es un cuerpo muerto de atributos o determinaciones, sino que la unidad de un proceso que comporta refiguraciones.

Curiosamente, y sobremanera en términos de cultura, sólo permanece con verdad, sólo sigue disponiendo de verdad interpelante, aquello que se transforma.

El «reino cadaveroso» — para recordar una expresión cara a António Sérgio ${ }^{19}$, que puede, con provecho, conocer alargamientos temporales y geográficos de su potencial semántico- no es (sólo en la aparencia, paradójicamente) un monu- mento a la Identidad, sino que una revisitación imaginaria de la parálisis, una enojosa liturgia del marasmo, una inepta marmolización de lo desvitalizado: no es siquiera memoria, es un falaz abreviativo del devenir.

Incluso el conservadurismo inteligente ha entendido bien el mensaje. Queda emblematica la confesión de Tancredi en Il Gattopardo: «Se vogliamo che tutto rimanga come è, bisogna che tutto cambi» ${ }^{20}$.

O sea, algo tiene que mudar para que lo esencial permanezca, pero no todo cambio es revolucionario ${ }^{21}$. Sin embargo, ésos son otros cuentos..

\section{7}

Es tiempo de concluir, volviendo a nuestro tema.

La identidad cultural no es un dato ya listo que simplemente se conserva, apiadadamente se purifica y majestuosamente se transmite. No es una ciudadela hacia la cual perezosamente se apunta siempre que presuntas hordas barbáricas redibujan la línea del horizonte. No es una trampa de recurso para conscripciones populistas de fervor patriotero o para enquistamientos acomodados en refinadas teorizaciones de la incomunicabilidad de las culturas.

La identidad cultural es algo mucho más serio, trabajoso y exigente. Ella es un índice, un instrumento y un campo de manifestación concretizada, y en concretización, de la calidad comunitaria de una protagonización histórica del vivir.

Por caminos distintos, pero no radicalmente contradictorios, tanto el enclaustramiento ombligo-contemplativo de «interioridades» venerandas como la pasmada importación mimética de «externalidades» dominantes atentan contra el ejercicio creador de una identidad que sólo se afirma, porque se hace. Uno de los ingredientes principales de la temida descaracteri- 
zación empieza, desde luego, por consistir en la falta o en el embotamiento del carácter.

La identidad cultural es un producto y una producción concretos: de relacionamientos, de diálogos, de conflictos también, de reconfiguraciones. Desde ellos, de dentro de ellos, una colectividad o un pueblo (reacuñando adquiridos y adquisiciones, cuestionando la marcha de su devenir, acarreando anhelos y contribuciones) sedimenta su experiencia histórica, trabaja el presente de su existencia, entreabre y posibilita las derivas de su porvenir.

Más que un tesoro de bienes intangible que se resguarda y lega, más que una fórmula altisonante de que a espacios se abusa, más que una memoria vaga que el utilismo cuotidiano trata de sumergir y estropear - la identidad cultural es, para un pueblo, el cuidado vivo y creador por su propia destinación, en un marco alargado y solidario de apertura al mundo y a lo(s) otro(s).

Decía Martin Buber que «el ser humano se vuelve yo en el tú» (Der Mensch wird am Du zum Ich) ${ }^{22}$. Algo semejante ocurre también con la constitución del «nosotros» de una comunidad, en su labor interna y externa de descubierta y de construcción.

El diálogo de las culturas, además de regla de convivencia y de cimiento de una paz sostenible, se despliega como manantial de enriquecimiento y de vitalización de la propia identidad.

Hablo de diálogo, no hablo de tolerancia incomunicante, ni de monería deslumbrada, ni de vasallaje unidireccional. Y acaece así porque el diálogo verdadero siempre se entabla en la base y en el marco de una historia que en conjunto se descubre, se trabaja, se transforma.

Toda comunidad es un trabajo histórico del ser por colectividades humanas. Produce y se produce como cultura, haciéndose cargo de su propia destinación en un ambiente procesual de distintos estímulos y relacionamientos.

Sólo en este marco de concreción la identidad asoma a un tiempo como unidad formada de multiplicidades, como expresión de una calidad sustancial alcanzada, como plataforma abierta a nuevos caminares.

\section{NOTAS}

1 «En efecto, lo que es se dice de muchas maneras»

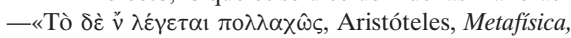
$\Gamma, 2,1003$ a 33 .

2 «Ora, la tesis es también problema» — «है $\tau \tau 1 \mu \varepsilon ̀ v$

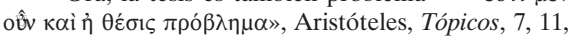
104 b 29 .

${ }^{3}$ Cf. José Saramago, A Jangada de Pedra, Lisboa, Editorial Caminho, 1986, p. 45.

${ }_{4}$ Cf. Javier Muguerza, «Proyecto de una nueva guía (ilustrada) de perplejos», Desde la Perplejidad. Ensayos sobre la ética, la rázon y el diálogo, México, Fondo de Cultura Económica, $1995^{2}$, p. 45.

${ }^{5}$ Cf. Benedictus Spinoza, Epistolae, L; Opera quoquot reperta sunt, eds. J. Van Vloten y J. P. N. Land, Den Haag, Martinus Nijhoff, $1914^{3}$, vol. III, p. 173

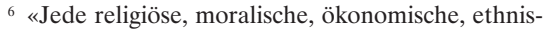
che oder andere Gegensatz verwandelt sich in einem politischen Gegensatz, wenn er stark genug ist, die Menschen nach Freund und Feind effektiv zu grup- pieren», Carl Schmitt, Der Begriff des Politischen (1932), 4; Berlín, Dunker \& Humblot, $1996^{6}$, p. 37.

7 «Identity at any level - personal, tribal, racial, civilizational- can only be defined in relation to an "other" [...]. The civilizational "us" and the extracivilizational "them" is a constant in human history. [...]. It is human to hate. For selfdefinition and motivation people need enemies», Samuel P. Huntington, The Clash of Civilizations and the Remaking of World Order, III, 6; London-New York, Touchstone Books, 1998², pp. 129 y 130

${ }^{8}$ Cf. Gilles Deleuze, Différence et Répétition, III Paris, Presses Universitaires de France, $1993^{7}$, pp. $179-180$.

9 «Das bloße Vorstellen reißt aber die Dinge aus ihrem konkreten Zusammenhange völlig heraus, vereinzelt dieselben», Georg Wilhelm Friedrich Hegel, Enzyklopädie der philosophischen Wissenschaften im Grundrisse, §398, Zusatz; Theorie Werkausgabe, red. 
Eva Moldenhauer y Karl M. Michel (adelante: TW), Frankfurt am Main, Suhrkamp, 1970, vol. 10, p. 93.

${ }_{10} \ll$ El intelecto, en tanto que medio para la conservación del individuo, despliega sus fuerzas principales en la disimulación» - «Der Intellekt als Mittel zur Erhaltung des Individuums entfaltet seine Hauptkräfte in der Verstellung»-, Friedrich Nietzsche, Über Warheit und Lüge im aussermoralischen Sinn, 7; Werke, ed. Karl Schlechta, Darmstadt, Wissenschaftliche Buchgesellschaft, $1973^{7}$, vol. III, p. 310.

11 «Il y a des différences internes qui dramatisent une Idée, avant de représenter un objet», G. Deleuze, Différence et Répétition, Introduction; Paris, Presses Universitaires de France, $1993^{7}$, p. 39.

${ }_{12} \mathrm{Cf}$. Hegel, Phänomenologie des Geistes; TW, vol. 3, pp. 567-568.

Véase también, puesto que el problema no es en exclusiva ontológico, Hegel, Über die wissenschaftlichen Behandlungsarten des Naturrechts, seine Stelle in der praktischen Philosophie und sein Verhältuis zu den positiven Rechtswissenschaften; TW, vol. 2, pp. 454-458.

${ }^{13}$ Cf. Karel Košik, Die Dialektik des Konkreten. Eine Studie zur Problematik des Menschen und der Welt, Frankfurt am Main, Suhrkamp, 1986², pp. 9-10.

${ }^{14}$ Cf. Martin Heidegger, Identität und Differenz, Vorwort, Pfullingen, Günther Neske, $1986^{8}$, p. 8.

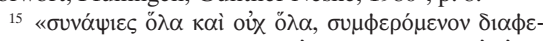

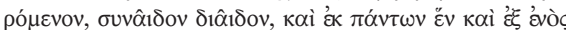

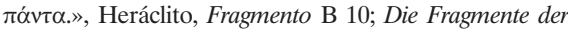
Vorsokratiker, ed. Hermann Diels y Walther Kranz, Berlin, Weidmann, $1956^{8}$, vol. I, p. 153.

${ }^{16}$ Cf. Jacques Derrida, «La différance» (1968), Marges de la philosophie, Paris, Éditions de Minuit, 1972, p. 11.

17 «L'identité de l'individu ne consiste pas à être pareil à lui-même et à se laisser identifier $d u$ dehors par l'index qui le désigne mais, à être le même -à être soi-même, à s'identifier de l'intérieur», Emmanuel
Lévinas, Totalité et Infini. Essai sur l'extériorité (1971), n. ed., Paris, Kluwer Academic/Poche, 1992, p. 321. 18 «Die abstrakte Identität mit sich ist noch keine Lebendigkeit [...]. Etwas ist also lebendig, nur insofern es den Widerspruch in sich enthält», Hegel, Wissenschaft der Logik; TW, vol. 6, p. 76.

${ }^{19}$ Cf. António Sérgio, O reino cadaveroso ou o problema da cultura em Portugal (1926); Obras Completas. Ensaios, ed. Castelo Branco Chaves, Vitorino Magalhães Godinho, Rui Grácio y Joel Serrão (adelante: OCE), Lisboa, Sá da Costa, 1972, vol. II, pp. 25-61.

Véase también la contundente ironía crítica dirigida hacia el llamado «espectrismo»: «Estes factores vivos de um momento que empedramos em absolutos, cadaverizados na eternidade, são os fantasmas que nos tiranizam, são as "larvas tumulares", são os Espectros", A. Sérgio, Espectros; OCE, vol. I, p. 173.

${ }^{20}$ Cf. Giuseppe Tomasi di Lampedusa, Il Gattopardo (1957), I; ed. Gioacchino Lanza Tomasi, Milano, Feltrinelli, $1998^{71}$, p. 41

${ }^{21}$ Como se dice en La Ideología Alemana, «no es la crítica, sino la revolución, la fuerza motriz de la historia» — «nicht die Kritik, sondern die Revolution die treibende Kraft der Geschichte [...] ist», Karl Marx y Friedrich Engels, Die deutsche Ideologie. Kritik der neuesten deutschen Philosophie in ihren Repräsentanten Feuerbach, B. Bauer und Stirner, und des deutschen Sozialismus in seinen verschiedenen Propheten, I; Marx-Engels Werke (adelante: MEW), Berlin, Dietz Verlag, $1969^{4}$, vol. 3, p. 38.

Todavía, si la transformación revolucionaria no dispensa a la "práctica humana» (menschliche Praxis), tampoco evacúa «el concebir de esa práctica» (das Begreifen dieser Praxis). Cf. K. Marx, Thesen über Feuerbach, 8; MEW, vol. 3, p. 7.

${ }_{22}$ Cf. Martin Buber, Ich und Du, I; Das dialogische Prinzip, Darmstadt, Wissenschaftliche Buchgesellschaft, $1994^{7}$, p. 32 . 